\title{
Prevalence and Associated Factors of Depression among General Outpatients in a Tertiary Institution in Kano, North-Western Nigeria
}

\author{
Auwal Sani Salihu1*, Owoidoho Udofia ${ }^{2}$ \\ ${ }^{1}$ Department of Psychiatry, Bayero University/Aminu Kano Teaching Hospital, Kano, Nigeria \\ ${ }^{2}$ Department of Psychiatry, University of Calabar/University of Calabar Teaching Hospital, Cross River State, \\ Nigeria \\ Email: *auwal01@yahoo.com
}

Received 28 March 2016; accepted 4 July 2016; published 7 July 2016

Copyright (C) 2016 by authors and Scientific Research Publishing Inc.

This work is licensed under the Creative Commons Attribution International License (CC BY). http://creativecommons.org/licenses/by/4.0/

(c) (7) Open Access

\section{Abstract}

Background: Depression is common psychiatric disorder among general outpatients. Prevalence of depression and associated factors among this population has been studied in some parts of Nigeria. However, few if any were conducted in the most populous geopolitical zone of Nigeria. Materials \& Method: This study determines the prevalence of depression and associated factors among general outpatients. It was a descriptive cross-sectional study. 402 of the 410 participants recruited for the study completed the study. Diagnosis of depression was confirmed using SCAN (Schedule for Clinical Assessment in Neuropsychiatry) ver. 2.1. Severity of depression was rated using HDRS (Hamilton Depression Rating Scale). Result: Two hundred were subsequently diagnosed depressed using SCAN out of 213 who scored HADS cutoff point, given the prevalence of $49.8 \%$. The prevalence of subtypes of depression was: Mild $26.9 \%$, moderate $20.4 \%$ and severe 2.5\%. A statistically significant association was found between depression and some socio-demographic factors which include age $\left(p=0.001, X^{2}=11.46\right)$, gender $\left(p=0.001, X^{2}=20.58\right)$, , marital status $\left(p=0.001, X^{2}=11.16\right)$, educational status $\left(p=0.001, X^{2}=10.8\right)$ and chronic medical conditions $\left(p=0.001, X^{2}=11.77\right)$. Depressed outpatient is more likely to be over $40 \mathrm{yrs}$, female, married, having low level of education and suffering from chronic medical condition(s). However, there was no significant association between depression and employment status, family history of mental illness and substance use in this study. Conclusion: This study found high prevalence of depression among general outpatients. It is associated with age, marital status educational level and chronic medical conditions. General practitioners should lookout for depression especially among patients with the associated socio-demographic factors. Some easy-to-use screening tools

\footnotetext{
${ }^{*}$ Corresponding author.
} 
like PHQ-2 should be included in the routine assessment of outpatients in Family Medicine departments. Task-sharing strategy as enshrined in mental health gap (mhGAP) document should be implemented to improve detection of depression at primary care level.

\section{Keywords}

\section{Depression, General Outpatients, Northwestern Nigeria, HADS}

\section{Introduction}

Depression occupies the $8^{\text {th }}$ place among the causes of DALYs [1] in low income countries, due to preponderance of (group I) communicable, maternal, peri-natal and nutritional conditions. However, it is projected to increase by $66 \%$ by the year 2030 , constituting a greater burden of disease than maternal, communicable, nutritional and peri-natal conditions in these countries [2] which include Nigeria. Despite this huge burden now and the projected burden in future, depression is under-detected and under-treated by General Practitioners (GPs) that are expected to do so for up to $90 \%$ of depressed patients in this population [3]. Depression among general outpatients has been studied by many researchers in Nigeria [4]-[6] and other parts of the world [7]. Some reported prevalence only along with other psychiatric morbidities [6] [8] and others included its associated factors [9]. The prevalence rates range from $11.7 \%$ to $34.4 \%$ in private general medical practice in Nigeria [3]. However, a recent study by Afolabi et al. in 2008 conducted at the family practice clinic of the Obafemi Awolowo University Teaching Hospital Complex (OAUTHC) where they used Zung's Self Rating Depression Scale on a sample of two hundred and fifty patients reported higher prevalence of 59.6\% [9]. Ihezue and Kumaraswamy of university of Nigeria Teaching Hospital, Enugu, used Zung's self rating Depression scale among 132 first time attendees of general outpatient clinic reported $14 \%$ score within the range of mild depression while $11 \%$ obtained scores within the range of moderate depression [6]. Another by study reported a much higher prevalence of $77 \%$ with mild, moderate and severe subtypes of depression of $62 \%, 14 \%$ and $1 \%$ respectively [10]. All these studies share methodological similarities, but the prevalence distinctively differs. Perhaps the use of screening instruments alone without unstructured, semi-structured or structured clinical psychiatric examination might account for the differences. This study set out to determine the prevalence of depression and its associated factors among general outpatients in Kano, North-western Nigeria.

\subsection{Depression, Socio-Demographics and Chronic Medical Conditions}

Socio-demographics have been found to be associated with depression. These include Gender [11] [12], Employment [13], Education [4] [14], and Age [15]. Many studies have also reported increased prevalence of depression among patients with chronic medical conditions like Diabetes, Hypertension, Asthma, Sickle cell disease, Cardiac diseases, Chronic Respiratory Diseases, and Rheumatoid arthritis [16].

\subsubsection{Gender and Depression}

Most studies found clear gender differences in the prevalence of depressive disorders. Bebbington and NolenHoesksema in two separate studies reported that women have a prevalence rate for depression up to twice that of men [11] [12]. This is true whether depression is indexed as a diagnosed mental disorder or as subclinical symptoms. The reason for this gender differences is not entirely clear [17]. However researchers believed could be accounted by such factors like trauma, victimization (sexual abuse), role overload (caring for children and elderly), poverty etc. [11]. Even when women and men are confronted with similar stressors, women may be more vulnerable than men to developing depression [11]. Women's greater reactivity to stress compared to men has been attributed to gender differences in biological responses, self-concept, and coping styles [11].

\subsubsection{Employment Status and Depression}

The association of depression and employment status has been reported in several studies. For instance, Comino et al. in a study among patients attending general practice in Australia reported that unemployed patients have an increased risk of developing depressive symptoms [13]. Similarly, Andersen et al. reported significant association between depression and unemployment [18]. However, in Nigeria Afolabi et al. found no significant re- 
lationship between depression and unemployment among general outpatients [9].

\subsubsection{Education and Depression}

Depression has a significant association with level of education. Some studies from Nigeria and other countries reported higher risk of depression among individuals with low level of education [4]. Ihezue and kumaraswamy [6], as well as Okulate [4] found that majority of depressed patients in Nigeria had low level of education. Similar findings were reported by Barkow et al. in an international prospective study (involving 15 countries of risk factors for depression in primary care) [14]. However, converse finding of more depressed among those with high level of education was reported in a community study in Canada [19]. Though the data was collected using unequal sampling probabilities.

\subsubsection{Age and Depression}

Depression is seen more commonly among younger than older patients [15]. Studies suggested a bimodal distribution of age of onset of depression [15]. Seventy percent of adults have their onset of depression before the age of 35 years and $25 \%$ after the age of 50 years [15]. The lowest predicted point was said to be at about 45 years of age. The higher incidence of depression in the young suggests that depression is due to large disparity between the perception of functional status and expectations [15]. However; despite the bimodal distribution the peaks are not equal. Depression is more among those who are aged 18 to 44 years than those over the age of 45 years [15]. Even though loneliness, diminished health and strength, and death of friends might be expected to lead to higher depression rates in the elderly [15]. Blanchflower et al. also reported that typical individual's happiness reached its minimum at about age 44 years [20].

\subsubsection{Marital Status and Depression}

Recent findings by Ifabumuyi who conducted a study at the Ahmadu Bello University Teaching Hospital, Zaria (very close to and share demographic similarities to Kano) on demographic characteristics of depressives in Northern Nigeria where he found that Depression was diagnosed more frequently in married women than single women [21]. Similarly, Brown et al. also reported that the beneficial effect of marriage was mainly to males than females [22].

\subsubsection{Family History of Mental Illness and Depression}

Ohaeri and Otote reported a study in Nigeria that family history of mental illness was associated with depression and significantly more common in psychotic or severe depression than in mild to moderate depression [23]. However factors such as that concealment of positive family history of mental illness was to avoid the disadvantage it confers in marriage and relationships may be considered in interpreting this finding [24].

\subsubsection{Chronic Medical Conditions (CMC) and Depression}

Chronic medical conditions and depressive disorders frequently co-occur. David et al. in a review article on the epidemiology, risk and treatment evidence of depression, anxiety and their relationship with chronic disease that depression is more common in all disease (CMC) groups than the general population [16]. Recent large worldwide population-based study found that people with chronic physical conditions were significantly more likely to have depression than were those without chronic conditions [25] Anderson et al. reported that the presence of diabetes double the odds of co-morbid depression, with diabetic women having significantly higher prevalence than diabetic men [18]. Similarly, findings from was Jos, Northern Nigeria by Agbir et al. showed that depression is a common psychiatric disorder among diabetic subjects with female-to-male ratio of 3:1 [26]. Studies on relationship between depression and hypertension showed a two-way association of hypertension being risk to development of depression and vice versa [27]. Hypertension is said to pose a risk for depression via some medication use to control the blood pressure such as beta blockers, methyldopa and diuretic [27]. While depression predispose to hypertension via natural dysregulation, hormonal dysregulation and life style changes [27]. Research has shown that individuals with asthma are more likely to be depressed than those without asthma [28]. Similar association was reported between depression and cardiovascular diseases with reported prevalence of major depression of between $17 \%$ and $27 \%$ in hospitalized patients [29].

\subsubsection{Substance Use and Depression}

Many studies reported that substance use coexists with a high frequency of cases of depressive disorders like 
that of Currie et al. conducted in Canada [30]. Kelder et al. too reported that the symptoms of depression were strongly and positively related to substance use in non-whites in particular [32]. However, Aiyelero et al. in ABUTH Zaria found very low history of substance use among depressed patient [32], though their finding could be attributed to the fact that the use of alcohol is prohibited in Islam which the predominant religion practice by majority of the people who reside in the area where the study was conducted.

\section{Material and Method}

The study was conducted at Aminu Kano Teaching Hospital (AKTH). It is located in Kano North-Western, Nigeria. The Department of Family Medicine which is located in accessible part of the hospital is the first-port-ofcall for non-emergency cases before referral to specialist clinics. This is a descriptive cross-sectional study. The study sample size was calculated based on the objective of determining the prevalence of depression among general outpatients using the formula $N=z^{2} p q / E^{2}$ [33], Where $N=$ minimum sample size, $Z=1.96$ (standard normal deviate for $95 \%$ confidence interval level), $p=$ proportion of population with condition studied (59.6\%) [9], $q=$ complementary probability $=(100-\mathrm{P})=(100-59.6)=40.4, \mathrm{E}=$ precision required (tolerable sampling error $)=5 \%$, Therefore, $\mathrm{N}=1.96^{2} \times 59.6(100-59.6) / 5^{2}=369.998$, approximately $=370$. Given attrition rate of $10 \%=370+10 / 100(370)=407 \approx 410$.

\subsection{Ethical Consideration}

An approval for the study was obtained from the research ethics committee of the AKTH, Kano State Nigeria.

\subsection{Inclusion/Exclusion Criteria}

Participation was entirely voluntary. Newly registered Patients on self-initiated visit who are 18 yrs and above, who gave consent and can read and write English or Hausa. Those receiving treatment for any psychiatric disorder, declined to give consent, too ill to take part and cannot read and write English or Hausa were excluded.

\subsection{Declaration of Interest}

The study was sponsored by the Aminu Kano Teaching Hospital as part of the mandatory residency training dissertation sponsorship.

\subsection{Sampling}

The sample was drawn using systematic random sampling method from all the patients who attended the general outpatient clinic for the first time, who met inclusion criteria and accepted to take part in the study. The list of all the newly registered patients formed the sampling frame. The study commenced from $1^{\text {st }}$ September to beginning $1^{\text {st }}$ November 2011.

\subsection{Procedure}

A pre-tested questionnaire (English/Hausa) containing socio-demographic information about the patient incorporated to HADS (hospital anxiety and depression rating scale (English/Hausa) was used to screen for depression. The Hamilton Depression Scale (HDS or HAMD or HDRS) was used to measure the severity of depressive symptoms in those confirmed to be depressed. A Schedule for Clinical Assessment in Neuropsychiatry (SCAN) version 2.1 was used to confirm the diagnosis of depression. A specially designed form containing four items asking the consulting physician to state the patient's presenting complaints, the medical diagnoses if any, symptoms of mental illness and the psychiatric diagnoses if present was also used. Four hundred and ten patients were selected from newly registered patients on self initiated visit attending out-patients clinic for the first time during the study period of eight weeks. All patients attending the clinic who were aged 18 years and above, who satisfied the inclusion criteria of this study were invited to participate. The SCAN interview was conducted by the researcher. Diagnoses generated by the SCAN software. Data was analyzed using the Statistical Package for Social sciences (SPSS) software for windows version 16. Proportions, percentages and ratios were determined as applicable. Classification into depressed and non-depressed categories was done based on SCAN interview result. Grading into mild, moderate and severe depression was additionally based on Hamilton depression rating 
scale (HDRS).

\section{Result}

Four hundred and ten (410) patients were selected for the study. However, $402(98.1 \%)$ of them finally participated. Table 1 shows that the mean age of the patients is 36.8 yrs (range 18 to 64 , sd 11.6). About one quarter (24.1\%) of them each were either not more than 25 years old or were above the age of 45 years. The gender distribution shows that more than half of the participants were females $(56.2 \%)$ while males constituted $43.8 \%$. The majority of the subjects $(80.4 \%)$ either had secondary education $(185,46.1 \%)$ tertiary education $(138,34.3 \%)$, while only $19.6 \%$ of them had primary education. Most of the participants were married $(230,57.2 \%)$. About $30 \%(119,29.6 \%)$ were single while the others were Separated (3.5\%), Widowed (3.2\%) or Divorced (6.5\%). Two-thirds $(269,66.9 \%)$ of the participants were unemployed while the remaining one-third $(133,33.1 \%)$ were employed. majority of the participants had no family history of mental illness $(313,92.8 \%)$. Only $29(7.2 \%)$ reported positive family history of mental illness. More than three-quarters of the participants a positive history of chronic medical condition $(313,77.9 \%)$ while only $22.1 \%$ of them had no history of chronic medical condition. Figure 1 shows One third of the participants suffered from hypertension. This was followed by participants with diabetes (18\%), cardiac disease (9\%), asthma (6\%), sickle cell disease and other respiratory conditions $4 \%$ each. Table 2 show that out of a total study population of four hundred and two participants, $200(49.8 \%)$ had a depressive disorder. Depression was more common among participants who were more than 45 yo $(60.2 \%, \mathrm{p}=$ $0.001)$, females $(59.7 \%, \mathrm{p}=0.001)$, married $(60 \%, \mathrm{p}=0.001)$, those with primary and/or secondary education $(55.7 \%, \mathrm{p}=0.001)$ and those with chronic medical conditions $(54.3 \%, \mathrm{p}=0.001)$.

\section{Discussion}

This study found the prevalence of $49.8 \%$ which is higher than the prevalence of $25 \%$ and $38.5 \%$ reported in an

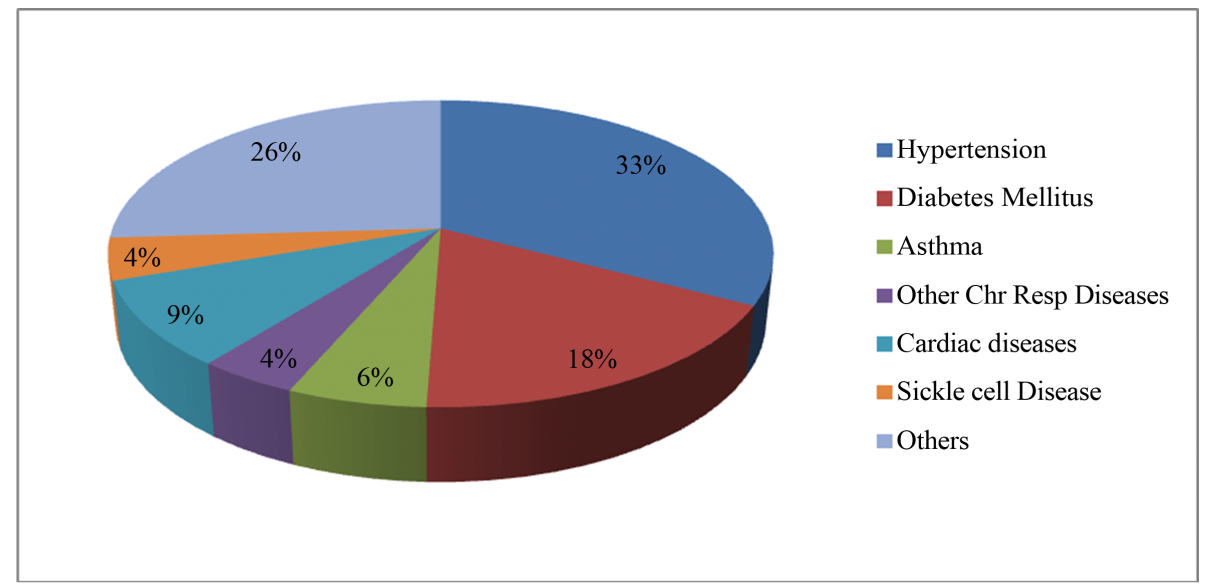

Figure 1. Pie chart illustrating chronic medical conditions reported by the participants $(n=313)$.

Table 1. Distribution of participants by age and gender.

\begin{tabular}{ccc}
\hline Age group & N & \% \\
$\leq 45$ & & \\
$>45$ & 305 & 75.9 \\
Gender & 97 & 24.1 \\
Male & & \\
Female & 176 & 43.8 \\
Total & 226 & 56.2 \\
\hline
\end{tabular}

Mean age $=36.8 \mathrm{yrs}, \mathrm{SD}=11.6$, range $=18-64$. 
Table 2. Association between depression and socio-demographics of the participants $(\mathrm{N}=402)$.

\begin{tabular}{|c|c|c|c|c|}
\hline Sociodemographic factors & Depressed n (\%) & Non-depressed n (\%) & $\chi^{2}$ & p value \\
\hline $\begin{array}{l}\text { Age } \\
\leq 45 \\
>45\end{array}$ & $\begin{array}{l}110(43.3) \\
90(60.2)\end{array}$ & $\begin{array}{c}144(56.2) \\
58(39.2)\end{array}$ & $11.46^{*}$ & 0.001 \\
\hline \multicolumn{5}{|l|}{ Gender } \\
\hline $\begin{array}{c}\text { Male } \\
\text { Female }\end{array}$ & $\begin{array}{c}65(36.9) \\
135(59.7)\end{array}$ & $\begin{array}{l}111(63.1) \\
91(40.3)\end{array}$ & $20.58^{*}$ & 0.001 \\
\hline \multicolumn{5}{|l|}{ Marital status } \\
\hline $\begin{array}{c}\text { Married } \\
\text { Unmarried }\end{array}$ & $\begin{array}{l}131(60.0) \\
69(40.1)\end{array}$ & $\begin{array}{l}99(43.0) \\
103(59.9)\end{array}$ & $11.16^{*}$ & 0.001 \\
\hline \multicolumn{5}{|l|}{ Educational status } \\
\hline $\begin{array}{c}1 \text { ry \& } 2 \text { ry level } \\
\text { Tertiary level }\end{array}$ & $\begin{array}{c}147(55.7) \\
53(38.4)\end{array}$ & $\begin{array}{l}117(44.3) \\
85(61.6)\end{array}$ & $10.8^{*}$ & 0.001 \\
\hline \multicolumn{5}{|l|}{ Employment status } \\
\hline $\begin{array}{c}\text { Employed } \\
\text { Unemployed }\end{array}$ & $\begin{array}{c}60(45.1) \\
140(52.0)\end{array}$ & $\begin{array}{c}73(54.9) \\
129(48.0)\end{array}$ & $1.71^{* *}$ & 0.200 \\
\hline \multicolumn{5}{|l|}{ Family History (FH) } \\
\hline $\begin{array}{l}\text { Positive FH } \\
\text { Negative FH }\end{array}$ & $183(49.1)$ & $\begin{array}{c}12(41.4) \\
190(50.9)\end{array}$ & $0.98^{* *}$ & 0.320 \\
\hline \multicolumn{5}{|l|}{ Substance use } \\
\hline $\begin{array}{c}\text { Never use } \\
\text { Use substance }\end{array}$ & $\begin{array}{c}188(49.2) \\
12(60.0)\end{array}$ & $\begin{array}{c}194(50.8) \\
8(40.0)\end{array}$ & $0.88^{* *}$ & 0.350 \\
\hline \multicolumn{5}{|l|}{ Chr. Med. conditions } \\
\hline $\begin{array}{c}\text { None } \\
\text { Present }\end{array}$ & $\begin{array}{c}30(33.7) \\
170(54.3)\end{array}$ & $\begin{array}{c}59(66.3) \\
143(45.7)\end{array}$ & $11.77^{*}$ & 0.001 \\
\hline
\end{tabular}

"significant, ${ }^{* *}$ not significant.

earlier studies conducted in Nigeria and China respectively [6] [7]. However, the prevalence of depression reported in the present study is lower than the rate of 59.6\% reported in a recent study by by Afolabi and his colleagues at OAUTHC, Ife [9]. It is also lower than the prevalence report in an earlier finding of $77 \%$ by Jegede among similar population of general outpatients at the UCH Ibadan [10]. These differences between the observed prevalence in this study conducted in north-western Nigeria and the figures cited from more recent Ife and earlier Ibadan study all conducted in south-western Nigeria among general outpatients population could be accounted for variously by differences like variations in local rates of predisposing factors for depression in the various communities which were ethnically and culturally diverse, as suggested by Judd et al. [34] and the methodological differences in the study designs. These studies both used self rating instruments (Zung depression rating scale), in contrast to this study in which both self rating instrument (HADS) and interview schedule (SCAN) were used. While the prevalence in those studies could only be compared with the proportion picked by the screening instrument (HADS) used in this study, the second stage design of this study gave more or less the true prevalence of depression in the Kano patients. The findings of this study revealed that the prevalence of depression among females was $33.7 \%$ compared to $16.2 \%$ among males, suggesting that depression was two times more common in females than males. Bebbington and Nolen-Hoeksema in two separate studies reported similar findings [11] [12]. The reason for this gender differences is not entirely clear [17]. Although most researchers today believe that it is a combination of several factors which include; the effects of oestrogen on stress hor- 
mone (cortisol), sexual assault as girls, chronic strains, higher poverty, and sexual harassment at work place, role overload and greater reactivity to stressors [11]. Also in this study, depression was more common among those over 45 years compared to those who were 45 years and below $(p=0.001)$. Over $60 \%$ of the participants above the age of 45 years were depressed. This is in agreement with recent findings of Blanchflower et al. who reported that typical individual's happiness reached its minimum at about age 44 years [20]. There was significant association between depression and marital status in this study (there were more married among the depressed than non-depressed $(\mathrm{p}=0.001)$ patients. This is similar to the findings of Ifabumuyi who conducted a study (very close and share demographic similarities to Kano) at the Ahmadu Bello University Teaching Hospital, Zaria on demographic characteristics of depressives in Northern Nigeria where he found that Depression was diagnosed more frequently in married women than single women [21]. In addition Brown et al. also reported that the beneficial effect of marriage was mainly to males than females [22]. In this study, depression was found to be common among patients with lower level of education. Depression was found in $36.6 \%$ patients with low level of education (primary and secondary) compared to $13.2 \%$ who had depression among those with tertiary education. This agrees with other findings of Ihezue et al. [6] and Okulate et al. [4] who reported that majority of depressed patients in Nigeria had low level of education. The employment status of the studied patients was found not to have a significant relationship with depression in this study $(p=0.20)$. This finding was contrary to previous report of significant association between employment status and depression [13]. However, this might be due to high unemployment status among the study subjects in addition to the finding of more than two third of the depressed patients were females who constitute most of the unemployed participants in this study. There was no significant association between depression and family history of mental illness $(p=0.320)$. This could be explained by earlier findings of Ohaeri and Otote [23] that family history was significantly more common in psychotic or severe depression meaning that those with family history have more severe illness while considering that only few $(5.5 \%)$ had severe depression, it was not surprising therefore there were few depressed patients with family history of mental illness. Another reason might be as Sale who worked in Kano for his part II dissertation on depression among HIV/AIDS patients reported that concealment of positive family history of mental illness was to avoid the disadvantage it confers in marriage and relationships, which might have played a role among these participants [24]. Substance use had no association with depression in this study $(p=0.35)$. This is contrary to many documented findings like that of Currie et al. who reported that substance use coexists with a high frequency of cases of depressive disorders in Canada [30]. Kelder et al. too reported that the symptoms of depression were strongly and positively related to substance use in non-whites in particular [31]. However, Aiyelero et al. in ABUTH Zaria found very low history of substance use among depressed patient [32]. This finding could be attributed to the fact that the use of alcohol is prohibited in Islam which the religion practices by majority the people who reside in the area where the study was conducted. Depression was found to be common among those with chronic medical conditions (CMC) (such as hypertension, chronic respiratory disease(s), diabetes mellitus etc) $(\mathrm{p}=0.001)$. One hundred and seventy $(42.3 \%)$ depressed had one or more chronic medical condition(s). This was as reported by David et al. in a review article on the epidemiology, risk and treatment evidence of depression, anxiety and their relationship with chronic disease that depression is more common in all disease (CMC) groups than the general population [16].

\section{Strength and Weakness}

This study used a combination of screening (HADS) and diagnostic instruments (SCAN). However, it is a cross sectional study and causal relationship cannot be attributed.

\section{Conclusion and Recommendations}

Prevalence of depression among general outpatients is very high therefore use of screening instrument like PHQ2 for depression at general outpatient department with the aim of improving its identification and treatment should be encouraged. Task-sharing strategy as enshrined in mental health gap (mhGAP) document should be implemented to improve detection of depression at primary care level.

\section{References}

[1] World Health Organisation: Global Burden of Disease: 2006. Part 4, 6-12.

http://www.who.int/healthinfo/global burden disease/GBD report 2004update full.pdf 
[2] Alan, D.L., Colin, D.M., Majid, E., Dean, T.J. and Christopher, J.L.M. (2006) Global Burden of Disease and Risk Factors. A Co-Publication of Oxford University Press and the World Bank, 355.

[3] Morakinyo, O. (2002) The Nature and Diagnosis of Depressive Disorders in Africans. Handbook for Mental health posting. Obafemi Awolowo University, Ile Ife, 68-69.

[4] Okulate, G.T. (1999) Psychiatric Morbidity in Private General Practice in Lagos, Nigeria. Nigerian Quarterly Journal of Hospital Medicine, 9, 124-126. http://dx.doi.org/10.4314/nqihm.v9i2.12392

[5] Gureje, O. and Simon, G.E. (1999) The Natural History of Somatisation in Primary Care. Psychological Medicine, 29, 669-676. http://dx.doi.org/10.1017/S0033291799008417

[6] Ihezue, U.H. and Khumaraswamy, N. (1986) Prevalence of Psychiatric Morbidity and Utilisation of Traditional Healers in General Outpatient Clinic. Acta Psychiatrica Scandinavia, 73, 395. http://dx.doi.org/10.1111/j.1600-0447.1986.tb02701.x

[7] Qin, X.X., Wang, W., Jin, Q., Ai, L., Li, Y.L., Dong, G.H., Liu, L. and Phillips, M.R. (2008) Prevalence and Rates of Recognition of Depressive Disorders in Internal Medicine Outpatient Department of 23 General Hospitals in Shenyang, China. Journal of Affective Disorders, 110, 46-54. http://dx.doi.org/10.1016/j.jad.2007.12.237

[8] Kessler, L.G., Cleary, P.D. and Burke, J.D. (1985) Psychiatric Disorders in Primary Care. Results of Follow up Study. Archive of General Psychiatry, 42, 583-587. http://dx.doi.org/10.1001/archpsyc.1985.01790290065007

[9] Afolabi, M.O., Abioye-kuteyi, E.A., Fatoye, F.O., Bello, I.S. and Adewuya, A.O. (2008) Pattern of Depression among Patients in a Nigerian Family Practice. South Africa Family Practice, 50, 63 (a-e). http://dx.doi.org/10.1080/20786204.2008.10873701

[10] Jegede, R.O. (1978) Depressive Symptomatology in Patients Attending a Hospital Based General Outpatient Clinic. African Journal of Medical Sciences, 7, 207-210.

[11] Bebbington, P.E. (1996) The Origins of Sex Differences in Depressive Disorder: Bridging the Gap. International Review of Psychiatry, 8, 295-332. http://dx.doi.org/10.3109/09540269609051547

[12] Nolen-Hoeksema, S. (1987) Sex Differences in Unipolar Depression: Evidence and Theory. Psychological Bulletin, 101, 259-282. http://dx.doi.org/10.1037/0033-2909.101.2.259

[13] Comino, E.J., Harris, E., Derrick, S., Vijaya, M. and Mark, F.H. (2000) Prevalence, Detection and Management of Anxiety and Depressive Symptoms in Unemployed Patients Attending General Practitioner. Australia \& New Zealand Journal of Psychiatry, 34,107-113. http://dx.doi.org/10.1046/j.1440-1614.2000.00645.x

[14] Barkow, K., Maier, W., Ustun, T.B., Gansicke, M., Wittchen, H.U. and Heun, R. (2003) Risk Factors for Depression at 12-Month Follow-Up in Adult Primary Health Care Patients with Major Depression: An International Prospective Study. Journal of Affective Disorder, 76, 157-169. http://dx.doi.org/10.1016/S0165-0327(02)00081-2

[15] Rohrbaugh, R.M., Sholomskas, D.E. and Giller Jr., E.L. (1989) Lifetime Course of Chronic Depression in Older Men. Journal of Geriatric Psychiatry and Neurology, 2, 89-95. http://dx.doi.org/10.1177/089198878900200207

[16] David, M.C. and Kay, C.C. (2009) Depression, Anxiety and Their Relationship with Chronic Diseases. A Review of the Epidemiology, Risk and Treatment Evidence. The Medical Journal of Australia, 190, S54-S60. https://www.mja.com.au/journal/2009/190/7/depression-anxiety-and-their-relationship-chronic-diseases-review-epide miology

[17] Murakami, J. (2002) Gender and Depression, Explaining the Different Rates of Depression between Men and Women. Perspectives in Psychology, 27-37.

[18] Andersen, I., Thielen, K., Nygaard, E. and Denchsen, F. (2009) Social Inequality in the Prevalence of Depressive Disorders. Journal of Epidemiology \& Community Health, 63, 515-587. http://dx.doi.org/10.1136/jech.2008.082719

[19] Akhtar-Danesh, N. and Landeen, J. (2007) Relation between Depression and Sociodemographic Factors. International Journal of Mental Health Systems, 1, 4. http://dx.doi.org/10.1186/1752-4458-1-4

[20] Blanchflower, D.G. and Oswald, A.J. (2009) The U-Shape without Controls: A Response to Glenn. Social Science \& Medicine, 69, 486-488. http://dx.doi.org/10.1016/j.socscimed.2009.05.022 http://www.sciencedirect.com/science/article/pii/S0277953609003074

[21] Ifabumuyi, I.O. (1983) Demographic Characteristics of Depressive in Northern Nigeria. Acta Psychiatrica Scandinavica, 68, 271-276. http://dx.doi.org/10.1111/j.1600-0447.1983.tb07007.x

[22] Brown, A.C., Brody, G.H. and Stoneman, Z. (2000) Rural Black Women and Depression: A Contextual Analysis. Journal of Marriage and Family, 62, 187-198. http://dx.doi.org/10.1111/j.1741-3737.2000.00187.x

[23] Ohaeri, J.U. and Otote, D.I. (2002) Family History, Life Events and the Factorial Structure of Depression in a Nigerian Sample of Inpatients. Psychopathology, 35, 210-219. http://dx.doi.org/10.1159/000063826

[24] Shehu, S. (2007) Prevalence and Factors Associated with Depression in HIV/AIDS Patients in Aminu Kano Teaching Hospital, Kano, Nigeria. A Dissertation Submitted to Faculty of Psychiatry, National Postgraduate Medical College of 
Nigeria.

[25] World Health Surveys (2007) Depression, Chronic Diseases, and Decrements in Health: Results from the World Health Surveys. The Lancet, 370, 851-858. http://dx.doi.org/10.1016/S0140-6736(07)61415-9

[26] Agbir, T.M., Audu, M.D., Adebowale, T.O. and Goar, S.G. (2010) Depression among Medical Outpatients with Diabetes: A Cross-Sectional Study at Jos University Teaching Hospital, Jos, Nigeria. Annals of African Medicine, 9, 5-10. http://dx.doi.org/10.4103/1596-3519.62617

[27] Zavaloni, S.A., Zavaloni, S.M., Serro, A.J.B. and Francisco, L.N. (2005) Hypertension and Depression. Clinics [Internet], 60, 241-250. http://www.scielo.br/scielo.php?script=sci_arttext\&pid=S1807-59322005000300010\&lng=en http://dx.doi.org/10.1590/S1807-59322005000300010

[28] Kessler, R.C., McGonagle, K.A., Zhao, S., Nelson, C.B., Hughes, M., Eshleman, S., Wittchen, H.U. and Kendler, K.S. (1994) Lifetime and 12-Month Prevalence of DSM-III-R Psychiatric Disorders in the United States. Results from the National Comorbidity Survey. Archive of General Psychiatry, 51, 8-19. http://dx.doi.org/10.1001/archpsyc.1994.03950010008002

[29] Rudisch, B. and Nemeroff, C.B. (2003) Epidemiology of Comorbid Coronary Artery Disease and Depression. Biological Psychiatry, 54, 227-240. http://dx.doi.org/10.1016/S0006-3223(03)00587-0

[30] Currie, S.R., Simon, G.E., William, J.V., Wang, J., et al. (2005) Comorbidity of Major Depression and Substance Use Disorders. Canadian Journal of Psychiatry, 50, 660-666.

[31] Kelder, S.H., Murray, N.G., Orpinas, P., Prokhorov, A. and McReynold, L. (2001) Depression and Substance Use in Minority Middle School Students. American Journal of Public Health, 91, 761-766. http://dx.doi.org/10.2105/AJPH.91.5.761

[32] Aiyelero, O.M., Kwanashie, H.O., Sheikh, T.L. and Hussaini, I.M. (2011) Some Socio-Demographic Features of Mood Disorders Presented by Patients Attending a Northern Nigeria Tertiary Health Institution Clinic. Journal of Applied Pharmaceutical Science, 1, 92-95. http://www.japsonline.com/admin/php/uploads/130 pdf.pdf

[33] Lwanga, S.K. and Lemeshow, S. (1991) Sample Size Determination in Health Studies: A Practical Manual. WHO, Geneva, 15.

[34] Judd, F.K., Jackson, H.J., Komiti, A., Murray, G., Hodgins, G. and Fraser, C. (2002) High Prevalence Disorders in Urban and Rural Communities. Australian \& New Zealand Journal of Psychiatry, 36, 104-107. http://dx.doi.org/10.1046/j.1440-1614.2002.00986.x

\section{Submit or recommend next manuscript to SCIRP and we will provide best service for you:}

Accepting pre-submission inquiries through Email, Facebook, Linkedin, Twitter, etc A wide selection of journals (inclusive of 9 subjects, more than 200 journals)

Providing a 24-hour high-quality service

User-friendly online submission system

Fair and swift peer-review system

Efficient typesetting and proofreading procedure

Display of the result of downloads and visits, as well as the number of cited articles

Maximum dissemination of your research work

Submit your manuscript at: http://papersubmission.scirp.org/ 